Session 2793

\title{
Synergistic Emerging Technologies and Exponential Change: Implications for Engineering Education
}

\author{
COL Kip P. Nygren \\ Professor, U.S. Military Academy
}

\begin{abstract}
Change is coming, it is coming faster than nearly everyone expects, and it cannot be stopped. The only sensible response is to enthusiastically embrace change and use it to advantage to improve overall organizational effectiveness. The synergistic blending of Nanoscale Engineering, Genetic Engineering and Robotics/Artificial Intelligence has the potential to change society in revolutionary ways. Correspondingly, these technologies will also profoundly change the nature of engineering education with the advent of computers that exceed the processing capability of the human brain, high quality virtual reality, and molecular manufacturing, among other possibilities. Equally unsettling for many is the notion that technological progress is advancing exponentially and, therefore, the pace of change is increasing. Education is the best possible solution for successfully responding to accelerating technological change and engineering education programs are particularly well suited to inspire this response. Engineering programs must set the example for students and society by becoming "learning organizations" and by embracing a process of continual transformation to successfully cope with accelerating technological change.

Introduction

The explosion of information technology during the last decade of the $20^{\text {th }}$ Century provided a glimpse of the speed and magnitude of the revolutionary technological changes that will profoundly transform society during the first two decades of the $21^{\text {st }}$ Century. As overall technological progress advances faster than nearly everyone expects, the rate of advance will only continue to increase in the future. How should institutions of higher education and engineering education in particular respond to the rapid changes in the society surrounding them?

The only rational response is to enthusiastically embrace change and use it to leverage improvements in the overall higher education process, because if higher education does not change, other educational systems and processes will step in to make current institutions of higher education irrelevant in the future. Paradoxically, education is the only means to prepare both individuals and organizations to successfully adapt to the fast pace of change in the world, but our institutions of higher education seem slow to practice what they profess.
\end{abstract}


Enormous advances have already been made in almost all areas of human endeavor during the twentieth century. Transportation, communications, science, engineering, medicine, manufacturing, computing and information technology among others have seen progress beyond anything dreamed of in 1900. It could be conservatively estimated that more has been learned about the universe and humanity during the past 100 years than during the previous 2000 years. However, the field of education has lagged feebly behind these revolutionary advances. It is even remarked by some that entering college students of today know less about the subjects of higher education than their predecessors of 100 year ago. While new knowledge is created at an exponential rate, our formal processes for the transfer of knowledge to new generations seem to have stagnated. Why have we not seen comparable improvements in the process of higher education? Or does higher education not need to change any differently than it has in the past?

Exponential Change

Will change in the twenty-first century be any different than change in the twentieth century? The answer is a resounding yes, because technological change is increasing exponentially. Broad agreement exists among experts concerning the general direction of the evolution of technology and that three emerging technologies will be the major forces behind change in this decade: Nanoscale Engineering, Genetic Engineering and Robotics/Artificial Intelligence. ${ }^{1}$ While the individual impact of each of these technologies will be far reaching, the synergistic blending of the three has the potential to change society in truly revolutionary ways. Correspondingly, these technologies will also profoundly change the nature of the engineering profession and of engineering education with the advent of computers that exceed the processing capability of the human brain, high quality virtual reality, and molecular manufacturing, among other possibilities. The Information Technology innovations of the 1990's will look tame compared to the technological revolution that will occur during the first decade of the $21^{\text {st }}$ Century wrought by the synergistic combinations of these emerging technologies.

The observation that technological progress is advancing exponentially and, therefore, the rate of change is increasing, has unusual implications because it is nonlinear. A review of the evolution of technology over the past century leads Ray Kurzweil to estimate the doubling period of overall technological progress during the twentieth century to be about ten years, equivalent to a seven percent rate of growth. ${ }^{2}$ If this is true then over ten doubling periods in the last century, technology became 1000 times more advanced. During the first decade of the twenty-first century, technological progress will double again, which means we will see the same amount of technological process during this decade that was experienced in the entire twentieth century.

How will this continual and accelerating technological change transform higher education? Can the current structure of engineering education evolve apace with technology? One thing is clear now, there are many serious competitors in the education and knowledge business who are already making inroads into the traditional forte of higher education. Internet degree programs abound and there are over 1,600 corporate universities in existence today. ${ }^{3}$ For the first time in their history, institutions of higher education have genuine competitors and they must learn to compete in a future where learning will be a continuous need for all in society. 
Implications for Engineering Education

A Quality Change Process. There is no educational discipline better positioned to successfully respond to accelerating change than engineering education, because the key to responding is a quality process for change. The Accreditation Board for Engineering and Technology (ABET) has already provided a framework, known as Engineering Criteria 2000, upon which to build and refine the processes that will be needed to adapt. However, this assessment process must be expanded upon and broadened to change the culture of engineering education into an organizational model for students perhaps best exemplified by the concept of a "Learning Organization" that has recently been heralded by the business community. According to David Garvin of the Harvard Business School, "A learning organization is an organization skilled at creating, acquiring, interpreting, transferring, and retaining knowledge, and at purposefully modifying its behavior to reflect new knowledge and insights."4

Just as a change or learning process is essential for organizations, it is even more important for individual students, faculty and staff. Garvin's definition of a learning organization when applied to individuals becomes a definition of education. The processes of acquiring, interpreting, and retaining knowledge and then purposefully modifying one's behavior to reflect new knowledge and insights are the fundamentals of education, which are generally not studied in the course of undergraduate engineering programs. Since life-long learning is a professional obligation for all engineers, then the quality of the individual learning process must be a primary focus of engineering education.

Currently, too much emphasis in engineering education is put on the transfer of content from teacher to student. The balance must shift to devote roughly the same resources to learning and practicing the processes of learning that we have devoted to teaching content. Most students have never been exposed to any models of the learning process, yet learning is what college professors excel at, even though they might not be able to articulate clearly their individual methods. This does not mean that knowledge of the physical world and the fundamental concepts that engineers use to model the world are not important. Both content and process are important for undergraduate engineers to acquire, interpret, and retain and then to modify their behavior as a result of this new knowledge of both the world and the learning process.

Students then need to see models of the learning organization in the leadership and operation of engineering programs. Although EC 2000 is a good start point, a learning organization should enlarge and enrich this sound foundation. It exhibits a respectful tradition of open discussion that not only welcomes new ideas on all issues, but also seeks to understand, and then it completes the process by acting on this new information to change its behavior. All members of the organization are encouraged to participate and contribute to this process of continuous adaptation and improvement. ${ }^{5}$ The idea of involving students in this process is probably the best means to model both the individual and the organizational behaviors we strive to teach.

Multidisciplinary Problem Solving and Design. No purely technical problems exist in the world. All authentic problems involve aspects of politics, social concerns, and economics as well as technology. Real problems have their own history and can also be correlated to 
analogous problems that have been faced in the past. Engineering programs are obliged to routinely organize broad multidisciplinary teams of students and faculty from across the campus that confront and solve genuine multidisciplinary problems.

Engineers will begin to understand that the true measure of an engineering design effort is not a specific technical performance, but rather a desired positive outcome for society. ${ }^{6}$ Such a desired societal result cannot be obtained without the wisdom and experience of political scientists, historians, social scientists, economists, cultural experts, and others on the team. The proficiency of such a diverse team will require skillful team organization, effective teamwork and adept leadership, a decidedly more difficult task to accomplish than with a team consisting only of engineers. ${ }^{7}$ Colleges and universities are particularly well suited to build multidisciplinary teams and networks for problem solving. One goal of all undergraduate educational programs should be to provide each student the experience of confronting real problems as a member of a true multidisciplinary team.

New Disciplines. An exciting aspect of the evolution of technology is the frequent creation of new engineering disciplines from the intersection of two or more established disciplines. Mechanical Engineering is currently attempting to redefine itself, due to the numerous connections and overlaps with other disciplines that have become apparent. For example, bio-engineering, nanoscale engineering, mechatronics and robotics are now considered part of the broad scope of mechanical engineering. The enlargement and continuous partitioning of all disciplines presents a dilemma for both undergraduates and engineering programs, since most institutions cannot offer all of the expanding number of engineering disciplines and students cannot be expected to be knowledgeable about a myriad of options.

Accreditation Changes. The need to balance the teaching of process with the current emphasis on content, to better understand the non-technical aspects of real world problems, and the expansion of engineering disciplines suggest a fundamental change is needed for professional engineering education. In accordance with other professional education programs, such as in Law or Medicine, the professional engineering degree should be shifted to the Master of Science degree level. The undergraduate experience can then be broadened for engineers to better prepare them for the integration of political, social and economic concerns into design Additionally, both the content and process fundamentals needed to prepare students not just for engineering but to become quality continuous learners and self-growers can be included to the curriculum.

Moral/ethical Considerations. Technology is and always will be a double-edged sword for society. As technology becomes more advanced on the positive edge of the blade so will it possess more potential for perils to society on the negative edge. In the wake of recent terrorist attacks, public safety has gained a new priority in an environment where it can no longer be assumed that individuals will take no deliberate actions leading directly to their own demise. The ethics of the design of technology with the potential for immense destruction acquires a significantly more important moral responsibility for engineers and for engineering education. The protection of the public will demand something akin to a benign abort mode for all design products with a potential for harm above a specified energy or lethality level. In other cases, access to the technology may be severely restricted and ethical standards for design engineers 
strictly adopted and rigidly enforced. Clearly, professional ethics will be of increasing importance to engineering education and the engineering profession in the future.

Growth and Development after Commencement

The critical need for learning throughout a lifetime will drastically expand the need for institutions of higher education to guide the perpetual growth and development of all people beyond their formal education. I suspect that what we now call formal education, obtained in residence at an institution of higher education, will blur with the concept of continuing education, especially as distance education via the Internet becomes more pervasive. Already this need has launched a for-profit education industry to include the development of numerous corporate universities, for-profit educational companies, and continuing education courses sponsored by numerous professional societies.

What should be the role for higher education institutions and engineering education in this growing need for continuous learning? The creation and transfer of knowledge is not the sole province of colleges and universities, however, in most cases research, teaching and learning at institutions of higher education are openly conducted and candidly shared in accordance with their mission of service to society. The highly lucrative knowledge industry will clearly grow and transform in many diverse ways in the future, because the needs will be broad and varied. The potential roles for engineering education are not clear, but I am concerned that the open creation and dissemination of knowledge by academic professionals might be substantially reduced or even lost in competition with other sectors of the knowledge industry. It is incumbent upon all academic educators to help evolve higher education in the most appropriate direction to continue the tradition of service to society.

\section{Conclusions}

The accelerating advance and increasing complexity of technology will put enormous strains on the capability of higher education to adapt to an uncertain future and still accomplish its traditional educational mission. Engineering education programs must embrace change and continuously transform to provide the most effective and efficient educational programs available for all ages and segments of society. The Education Process is the key to this continuous transformation and everything about the conduct of higher education should be a model of those characteristics and abilities that we desire students to develop. Engineering program leaders are well positioned through the established ABET accreditation assessment process to lead higher education in the establishment of institution wide assessment programs and their transformation into genuine learning organizations.

Teachers, students and staff all at levels of the higher education institution must become better and better at learning and at modifying their behaviors in light of new knowledge and insights. A detailed discussion of the processes that can help accomplish these changes is beyond the scope of this article. However, the dialogue concerning transformation must be joined now because the unrelenting advance of technological change cannot be stopped. 


\section{References}

${ }^{1}$ Philip S. Anton, Richard Silberglitt, and James Schneider, The Global Technology Revolution:

Bio/Nano/Materials Trends and Their Synergies with Information Technology by 2015, first ed. (Santa Monica, CA: RAND, 2001), Committee on Issues Identification, New Dimensions in Multidisciplinary Thinking: Issues, Trends, and Implications for Mechanical Engineers and Asme (Waltham, MA: American Society of Mechanical Engineers, Council on Public Affairs, Global Foresight Associates, 2001), Ray Kurzweil, The Age of Spiritual Machines: When Computers Exceed Human Intelligence (New York: Penguin Books, 1999).

${ }^{2}$ Ray Kurzweil, The Singularity Is Near: A Book Precis, (Kurzweilai.net, 2001, accessed 16 August 2001); available from http://www.kurzweilai.net/articles/art0134.html.

${ }^{3}$ Corporate University Xchange, Survey of Corporate University Future Directions (9 January 1998, accessed 8 January 2002); available from http://www.corpu.com/research_services.html.

${ }^{4}$ David A. Garvin, Learning in Action: A Guide to Putting the Learning Organization to Work, 1st ed. (Boston, MA: Harvard Business School Press, 2000).

${ }^{5}$ Ibid.

${ }^{6}$ David H. Guston and Daniel Sarewitz, "Real-Time Technology Assessment," Technology in Society 23, no. 4 (2001).

77 Julie Younglove-Webb and others, "The Dynamics of Multidisciplinary Research Teams in Academia," The Review of Higher Education 22, no. 4 (1999).

\section{KIP NYGREN}

Professor and Head of the Department of Civil \& Mechanical Engineering at the US Military Academy since 1995, he has served on the faculty since 1987. He earned a PhD in Aerospace En gineering at Georgia Tech in 1986. Current interests include the interaction of technology and society, the history of technology, and engineering education. 